Journal of Engineering and Applied Sciences 5 (5): 354-360, 2010

ISSN: 1816-949X

(C) Medwell Journals, 2010

\title{
Analysis of Electrochemical Grinding Process While Machining Alumina-Aluminum Interpenetrating Phase Composites Using Grey-Taguchi Method
}

\author{
Goutam Kumar Bose \\ Department of Mechanical Engineering, Haldia Institute of Technology, Haldia, \\ Purba Medinipur, 721657 West Bengal, India
}

\begin{abstract}
The present study attempts to optimize machining parameters of Electrochemical grinding while machining alumina-aluminum interpenetrating phase composites by Grey-taguchi methodology. Control parameters like electrolyte concentration, voltage, depth of cut and electrolyte flow rate have been considered to ensure 2 conflicting responses higher material removal rate and lower surface roughness simultaneously by a single parametric combination. The $\mathrm{L}_{9}$ orthogonal array design is followed for the purpose of experimentation. The well known $\mathrm{S} / \mathrm{N}$ ratio analysis is performed along with ANOVA to establish the prominent variables that govern the responses separately. Finally, grey relational analysis is performed to optimize multiple performances in which different levels combinations of the factors are ranked based on grey relational grade. Surface roughness is given more importance than the MRR considering basic objective of the process. The analysis reveals that substantial improvement in machining performance takes place following this technique.
\end{abstract}

Key words: Electrochemical grinding, taguchi method, signal-to-noise ratio, grey relational analysis, machining performance, India

\section{INTRODUCTION}

Manufacturing industries all across the globe is passing through the dramatic changes caused by globalization, rapid proliferation in communication and IT enabled services. These changes essentially call for several modifications in the traditional way of working to survive in this complex business environment. Use of emerging and non-conventional techniques of machining and alternative materials is one of the major steps to cope with the changes. Electrochemical Grinding (ECG), a useful non-conventional hybrid machining process, used for machining difficul-to-machine alloys, hardened, fragile and thermal sensitive parts (El-Hofy, 2005). The material removal is a dual effect of electrochemical dissolution and mechanical grinding and found to be superior over conventional grinding.

The growing use of electrochemical grinding as compared to the conventional grinding is based upon several fundamental advantages of the process. ECG has high material removal rate as compared to the conventional grinding when working with the tough-tomachine materials such as high temperature resistant $\mathrm{Co}-$ $\mathrm{Ni}$ alloys, high tensile strength materials etc. (Benedict, 1987). The material removal in the ECG process can be attributed to purely mechanical abrasion electrochemical removal combined with mechanical abrasion with zero over cut electrochemical removal coupled with mechanical means with over cut $>0$ and absolutely electrochemical reaction (Atkinson and Nobel, 1987). While comparing between electrochemical and mechanical grinding, it is found that the ECG process has some advantages like enhanced material removal rate, reduced risk of thermal damage and less wheel wear. Input variables like voltage, electrolyte flow rate, electrolyte concentration and depth of cut significantly contribute to both Material Removal Rate (MRR) and surface finish $(\mathrm{Ra})$. Few research works have been carried out to establish the optimal process variables so as to achieve better surface finish and higher material removal rate (Bhowmick and Mishra, 2000; Reddy et al., 2000). Nevertheless, there is hardly any mathematical model involving process variables that can successfully describe neither MRR nor Ra. Both the objective being conflicting in nature, it is very difficult to achieve them simultaneously by a single set of process variables. The present research is aimed at optimization of process variables in regard to high MRR and good $\mathrm{Ra}$ concurrently following grey relational analysis technique.

\section{MATERIALS AND METHODS}

The Taguchi method is a well organized approach to improve product/process design by optimizing a single response through level settings of significant parameters that affect the response (Taguchi, 1986; Phadke, 1989; 
Park, 1996). However, increase in process variables eventually augments the number of experiments to be conducted, thereby increasing the time and cost. To get rid of such situations, the Taguchi method recommends that a small numbers of experiments using special design orthogonal arrays are sufficient for this purpose. $\mathrm{S} / \mathrm{N}$ ratio is one of the major attributes of Taguchi based quality engineering that is based on the premise of variability reduction and the improvement of measurement (Montgomery, 2003).

Based on the nature of objective (s), it can have 3 distinct categories higher the better, lower the better and nominal-the-better. Nevertheless, the larger $\mathrm{S} / \mathrm{N}$ ratio is always favorable irrespective of the above categories. Although, this procedure yield very good result for a single performance characteristic with great ease, it is difficult for optimizing several responses simultaneously which are contradicting in nature. This necessitates computation of an overall $\mathrm{S} / \mathrm{N}$ ratio by suitable transformation function. Such problems, however can be solved successfully following Grey Relational Analysis (GRA).

The grey system theory was proposed by Deng (1989) and it is widely used for analyzing a system in which the model is uncertain or the information is incomplete implying a combination of known and unknown information (Lin and Liu, 2004; Lu and Wevers, 2007). It also provides an efficient solution to complicated interrelationships among multiple response parameters (Wang et al., 1996). Based on the grey theory, a system can be investigated by means of relational coefficient, relational grade so as to take final decision regarding selection of optimum variables combination based on highest grade. The grey relational analysis is very much effective to evaluate the multiple response parameters by converting individual responses to a single grey relational grade.

Lu et al. (2008) used this technique to establish optimal cutting parameters while rough cutting processes in side milling for SKD61 tool steels to improve tool life and MRR by 54 and $9.7 \%$, respectively employing low spindle speed, moderate level of feed per tooth and radial depth of cut while maintaining highest level of depth of cut. Kuo et al. (2008) followed this approach for an IC packaging company in order to find out the best plant layout among 18 alternatives by considering 6 attributes and for a hybrid flow shop environment for ranking nine dispatching rules having five attributes. Lin and Lin (2002) optimized the process variables like work piece polarity, pulse on time, duty factor, open discharge voltage, discharge current and dielectric fluid on the responses such as material removal rate, surface roughness and electrode wear ratio following GRA while machining SKD11 alloy steel by copper electrode in EDM. The analysis shows significant improvements in performances following optimized process variables combination. Tsao (2009) adopted Grey-taguchi method to optimize milling parameters while machining A6061P-T651 aluminum alloy so as to reduce surface roughness and flank wear. Lin (2004) recommended low level of cutting speed, feed and depth of cut to enhance tool life and to reduce cutting force and surface roughness during turning of S45C steel by P20 tungsten carbide inserts. Few other similar researches are available by Yan-Min et al. (2007) and Kao and Hocheng (2003).

Plan of experimentation: In this study, an experimental study has been carried out on specimen of aluminaaluminum interpenetrating phase composites material to optimize the machining parameters of electrochemical grinding for maximum MRR and minimum Ra following GRA. During machining of composite materials by ECG, MRR and Ra have got different grades of importance. In case of finishing operation Ra is given more priority than MRR. These conflicting response parameters require different levels setting of the machining parameters for their optimization.

So proper machining parameter set up for simultaneous optimization of the responses is critical. When performing an experiment, varying the levels of the factors simultaneously rather than one at a time is efficient in terms of time and cost and also allows for the study of interactions between the factors. Based on past research and preliminary investigation, 4 parameters i.e., electrolyte Concentration (C), Voltage (V), Depth of cut (D) and electrolyte Flow rate $(\mathrm{F})$ have been chosen as input parameters. $\mathrm{A} \mathrm{L}_{9}$ orthogonal array is employed for the experimentation.

The input parameters were varied with three levels in nine experimental run. According to GRA technique, the characteristic that a larger value represents the better machining performance, such as higher MRR is called larger the better type problem. On the other hand, the characteristic that smaller value indicates better machining performance such as Ra is addressed as smaller the better type problem. Table 1 exhibits the different levels of control parameters during machining operation. Other factors like feed, types of power supply, electrolyte temperature which may affect the measured performance were kept constant during experimentation. Sodium chloride solution was used as electrolyte. The work piece was a flat rectangular plate of dimension $23 \times 15 \times 5 \mathrm{~mm}$ thick. Power supply maintained was D.C continuous. In the present research, a diamond impregnated metal 
Table 1: Input variables with their levels

\begin{tabular}{|c|c|c|c|c|}
\hline \multirow[b]{2}{*}{ Input variables } & \multirow[b]{2}{*}{ Units } & \multicolumn{3}{|l|}{ Levels } \\
\hline & & 1 & 2 & 3 \\
\hline Concentration (C) & $\mathrm{g}^{-1}$ lits & 20.00 & 25.00 & 30.00 \\
\hline Voltage (V) & Volts & 15.00 & 20.00 & 25.00 \\
\hline Depth of cut (D) & $\mathrm{mm}$ & 0.04 & 0.08 & 0.12 \\
\hline $\begin{array}{l}\text { Electrolyte } \\
\text { Flow rate }(\mathrm{F})\end{array}$ & lits/sec & 0.10 & 0.20 & 0.30 \\
\hline
\end{tabular}

Table 2: Properties of the alumina-aluminium IPC work material

\begin{tabular}{ll}
\hline Properties & $\begin{array}{l}\text { Values (Synthesis condition } \\
\text { is } 11500^{\circ} / 24 \mathrm{~h} \text { ) }\end{array}$ \\
\hline Compressive strength (MPa) & 576 \\
Micro hardness no.(VHN) & 364 \\
Bend strength (MPa) & $458 \pm 15$ \\
Elastic modulus (GPa) & 67 \\
Fracture origin: Principal & Separation at $\mathrm{Al}_{2} \mathrm{O}_{3} / \mathrm{Al}$ \\
& grain boundary \\
Bulk density (gm cm & 3.54 \\
Conductivity $\left(105 \mathrm{ohm}^{-1}\right.$ & 0.4 \\
$\mathrm{~cm}^{-1}$ at RT) & \\
Grain size (micron) & $\mathrm{Al}_{2} \mathrm{O}_{3}-4.27$ and $\mathrm{Al}-1.42$ \\
\hline
\end{tabular}

bonded grinding wheel of $150 \mathrm{~mm}$ diameter and $12.27 \mathrm{~mm}$ width was used. The width of the layer containing the diamond was $3 \mathrm{~mm}$ and the abrasive grit size was 100 . A DC motor rotating at a speed of $3500 \mathrm{rpm}$ drove the grinding wheel mounted at the end of the spindle. During machining, current was recorded that appeared on the ammeter connected to the electrical circuit. Figure 1 shows the machining setup with feed drive mechanism attachment. A microprocessor based controller unit controls the feed drive mechanism of the worktable during grinding. A stepper motor (Type: STM-1100) having torque $10 \mathrm{~kg} \mathrm{~cm}$ and angular resolution of $1.8 \%$ step with voltage phase: 24 VDC and current phase: 0.67 Ampere was used for the feed drive mechanism of the worktable.

Mechanical and other properties of work piece material i.e., $\mathrm{Al}_{2} \mathrm{O}_{3} / \mathrm{Al}$ interpenetrating phase composites are exhibited in Table 2 . MRR was measured by dividing the difference in weight of the workpiece before and after machining by the time duration of machining. An electronic weighing machine of accuracy $0.02 \mathrm{mg}$ of mettler toledo make (model no-AG285) was used for this purpose. Ra was measured with perthometer-M1 of mahr gmbh make.

Orthogonal array experiment: To select an appropriate orthogonal array for experiments, the total degrees of freedom need to be computed. The degrees of freedom are defined as the number of comparisons between machining parameters that need to be made to determine which level is better and specifically how much better it is. For example, a three-level machining parameter counts for 2 degrees of freedom. The degrees of freedom associated with interaction between 2 machining parameters are

\begin{tabular}{|c|c|c|c|c|c|c|}
\hline \multirow{3}{*}{$\begin{array}{l}\text { Experiment } \\
\text { no. }\end{array}$} & \multirow{2}{*}{\multicolumn{4}{|c|}{ Control parameters }} & \multicolumn{2}{|l|}{ Responses } \\
\hline & & & & & \multirow{2}{*}{$\begin{array}{l}\text { MRR } \\
\left(\mathrm{g} \min ^{-1}\right)\end{array}$} & \multirow{2}{*}{$\begin{array}{l}\mathrm{Ra} \\
(\mu \mathrm{m})\end{array}$} \\
\hline & $\mathrm{C}$ & $\mathrm{V}$ & $\mathrm{D}$ & $\mathrm{F}$ & & \\
\hline 1 & 20 & 15 & 0.04 & 0.1 & 0.067 & 0.168 \\
\hline 2 & 20 & 20 & 0.08 & 0.2 & 0.141 & 0.214 \\
\hline 3 & 20 & 25 & 0.12 & 0.3 & 0.053 & 0.837 \\
\hline 4 & 25 & 15 & 0.08 & 0.3 & 0.125 & 0.195 \\
\hline 5 & 25 & 20 & 0.12 & 0.1 & 0.151 & 0.516 \\
\hline 6 & 25 & 25 & 0.04 & 0.2 & 0.079 & 0.924 \\
\hline 7 & 30 & 15 & 0.12 & 0.2 & 0.373 & 0.206 \\
\hline 8 & 30 & 20 & 0.04 & 0.3 & 0.524 & 0.157 \\
\hline 9 & 30 & 25 & 0.08 & 0.1 & 0.093 & 0.402 \\
\hline
\end{tabular}

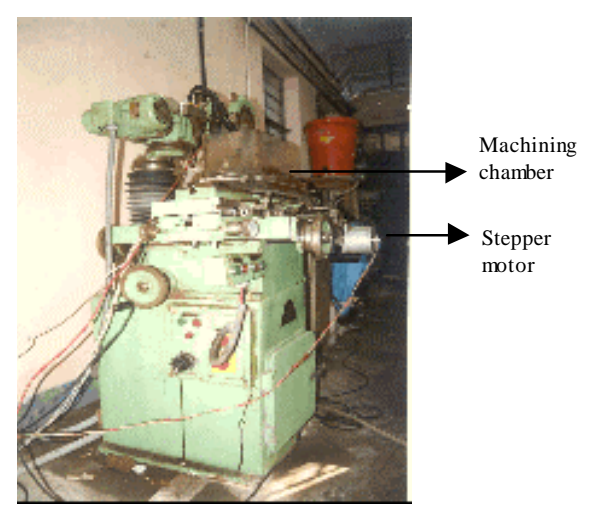

Fig. 1: The machining setup

given by the product of the degrees of freedom for the 2 machining parameters. In the present study, the interaction between the machining parameters is neglected. An $\mathrm{L}_{9}$ orthogonal array with 4 columns and 9 rows is used. This array has eight degrees of freedom and it can handle three-level process parameters. Nine experiments are required to study the entire linear motion guide parameter space when the $\mathrm{L}_{9}$ orthogonal array is used. The experimental layout for the machining parameters using the $\mathrm{L}_{9}$ orthogonal array along with the responses is shown in Table 3 .

\section{RESULTS AND DISCUSSION}

In this study, the experimental results are analyzed to investigate the contribution of different process variables on various responses by using $\mathrm{S} / \mathrm{N}$ ratio and ANOVA. The $\mathrm{S} / \mathrm{N}$ ratio converts several repetitions into one value that manifests the amount of variations and the mean response.

The ANOM is an important and potential technique to establish the prominence of various factors and their levels (main effects) on the response. The optimum level of a factor is the level that provides highest values of $\mathrm{S} / \mathrm{N}$ ratio. ANOVA is a statistical technique that helps estimate the significance of variables by variance ratio (F-value) and to compute $\%$ contribution of each factor. 
Analysis of test results for MRR: The Signal to Noise ratio $(\mathrm{S} / \mathrm{N})$ analysis for $\mathrm{MRR}\left(\mathrm{g} \mathrm{min}^{-1}\right)$ is carried out on the basis of larger is the better option. The corresponding $\mathrm{S} / \mathrm{N}$ ratio is expressed as:

$$
\eta_{1}=-10 \log _{10}\left(\frac{1}{\mathrm{n}} \sum_{\mathrm{i}=1}^{\mathrm{n}} \frac{1}{\mathrm{MRR}^{2}}\right)
$$

The $\mathrm{S} / \mathrm{N}$ ratio for MRR is shown in Table 4 . It is observed that voltage and electrolyte concentration both has significant effects on MRR while depth of cut and flow rate has marginal effect. The $\mathrm{S} / \mathrm{N}$ ratio plot for $\mathrm{MRR}$ is shown in Fig. 2.

The best combination for higher MRR is C3-V2-D3-F2. The average of factor levels for MRR is shown in Table 5 which helps conclude the aforementioned parametric combinations for optimum result. Table 6 shows the ANOVA results for MRR.

The $\mathrm{S} / \mathrm{N}$ ratio findings are also corroborated by ANOVA results as exhibited from $\mathrm{F}$-values and \% contribution of the process variables.

Analysis of test results for Ra: The Signal to Noise ratio ( $\mathrm{S} / \mathrm{N}$ ) analysis for $\mathrm{Ra}$ (micron) is modeled on the basis of smaller is the better. The corresponding $\mathrm{S} / \mathrm{N}$ ratio is expressed as:

$$
\eta_{2}=-10 \log _{10}\left(\frac{1}{\mathrm{n}} \sum_{\mathrm{i}=1}^{\mathrm{n}} \mathrm{R}_{\mathrm{a}}^{2}\right)
$$

Table 4: S/N ratio table for MRR

\begin{tabular}{lcccc}
\hline Level & C & V & D & F \\
\hline 1 & -22.0029 & -16.7020 & -17.0464 & -20.1764 \\
2 & -18.8432 & -13.0165 & -18.5693 & -15.8763 \\
3 & -11.6032 & -22.7308 & -16.8336 & -16.3966 \\
Delta & 10.3997 & 9.7143 & 1.7357 & 4.3001 \\
Rank & 1 & 2 & 4 & 3 \\
\hline
\end{tabular}

Table 5: Sum of MRR S/N ratios at each level of each factor

\begin{tabular}{|c|c|c|c|c|c|}
\hline $\begin{array}{l}\text { Process } \\
\text { parameter }\end{array}$ & $\mathrm{DOF}$ & $\begin{array}{l}\text { Sum of } \\
\text { squares }\end{array}$ & $\begin{array}{l}\text { Adjusted } \\
\text { mean } \\
\text { square }\end{array}$ & F-value & Contribution $(\%)$ \\
\hline $\mathrm{C}$ & 2 & 170.555 & 85.2780 & 8.877 & 48.28 \\
\hline V & 2 & 144.296 & 72.1480 & 7.510 & 40.84 \\
\hline $\mathrm{D}$ & 2 & 5.377 & 2.6880 & 0.280 & 1.50 \\
\hline $\mathrm{F}$ & 2 & 33.049 & 16.5250 & 1.720 & 9.35 \\
\hline Error & 0 & 0.000 & 0.0000 & - & - \\
\hline Total & 8 & 353.277 & - & - & - \\
\hline Error & 4 & 38.426 & 9.6065 & - & - \\
\hline
\end{tabular}

\begin{tabular}{lcccc}
\hline & Factors & & & \\
Level & - & & & \\
\hline-1 & -66.0086 & -50.1061 & -51.1394 & -60.5293 \\
0 & -56.5298 & -39.0495 & -55.7077 & -47.6289 \\
1 & -34.8095 & -68.1923 & -50.5008 & -49.1897 \\
Total & -157.3480 & -157.3480 & -157.3480 & -157.3480 \\
\hline
\end{tabular}

The $\mathrm{S} / \mathrm{N}$ ratio for $\mathrm{Ra}$ is shown in Table 7 . It is found from delta-values of the process variables that voltage is the most influencing parameter that governs $\mathrm{Ra}$ considerably. The overall ranking is showed in Table 7.

The $\mathrm{S} / \mathrm{N}$ plot for Ra is shown in Fig. 3. The best combination for lower Ra is C3-V1-D2-F3. The average of factor levels for Ra is shown in Table 8 to justify the significance of various operational parameters and their levels.

The findings of $\mathrm{S} / \mathrm{N}$ ratio are supported by ANOVA results shown in Table 9. The F-value of voltage stands at healthy 9.685 having $\%$ contribution of 68.91 as evident from ANOVA. The \% contribution of depth of cut and concentration are 11.98 and 16.86 , respectively.

Multi-objective model using Grey relational analysis: The main procedure of Grey Relational Analysis (GRA) is firstly translating the performance of all alternatives into a comparability sequence. This step is called Grey relational generating. According to these sequences, a reference sequence (ideal target sequence) is defined. Then, the grey relational coefficient between all comparability sequences and the reference sequence is calculated.

Finally, based on these grey relational coefficients, the grey relational grade between the reference sequence and every comparability sequences is calculated. If a comparability sequence translated from an alternative has

Table 7: $\mathrm{S} / \mathrm{N}$ ratio table for $\mathrm{Ra}$

\begin{tabular}{lcccc}
\hline Level & $\mathrm{C}$ & $\mathrm{V}$ & $\mathrm{D}$ & \multicolumn{1}{c}{$\mathrm{F}$} \\
\hline 1 & 10.1437 & 14.4719 & 10.7541 & 9.7188 \\
2 & 6.8776 & 11.7402 & 11.8355 & 9.2670 \\
3 & 12.5734 & 3.3825 & 7.0051 & 10.6089 \\
Delta & 5.6958 & 11.0894 & 4.8305 & 1.3420 \\
Rank & 2 & 1 & 3 & 4 \\
\hline
\end{tabular}

Table 8: Sum of Ra S/N ratios at each level of each factor

\begin{tabular}{llccc}
\hline & Factors & & & \\
Level & C & V & D & F \\
\hline-1 & 30.4310 & 43.4158 & 32.2624 & 29.1563 \\
0 & 20.6329 & 35.2207 & 35.5065 & 27.8010 \\
1 & 37.7202 & 10.1476 & 21.0152 & 31.8268 \\
Total & 88.7841 & 88.7841 & 88.7841 & 88.7841 \\
\hline
\end{tabular}

Table 9: ANOVA for surface roughness (Ra)

\begin{tabular}{lcrccc}
$\begin{array}{l}\text { Process } \\
\text { parameter }\end{array}$ & DOF & $\begin{array}{c}\text { Sum } \\
\text { of squares }\end{array}$ & $\begin{array}{c}\text { Adjusted } \\
\text { mean square }\end{array}$ & F-value & $\begin{array}{c}\text { Contribution } \\
(\%)\end{array}$ \\
\hline C & 2 & 49.012 & 24.506 & 2.370 & 16.86 \\
V & 2 & 200.289 & 100.144 & 9.685 & 68.91 \\
D & 2 & 38.558 & 19.279 & 1.864 & 11.98 \\
F & 2 & 2.797 & 1.399 & 0.135 & 0.96 \\
Error & 0 & 0.000 & 0.000 & - & - \\
Total & 8 & 290.657 & - & - & - \\
Error & 4 & 41.355 & 10.340 & - & - \\
\hline
\end{tabular}




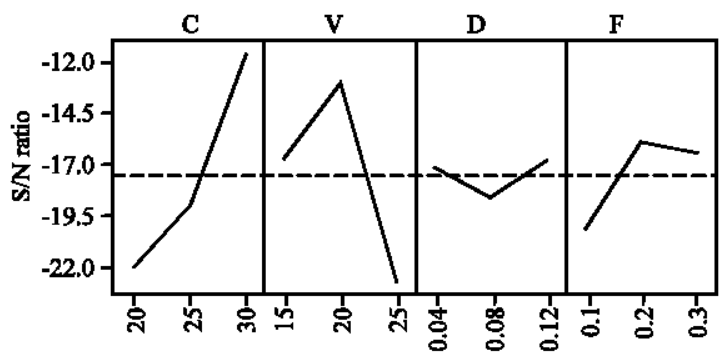

Fig. 2: $\mathrm{S} / \mathrm{N}$ ratio graph for $\mathrm{MRR}$

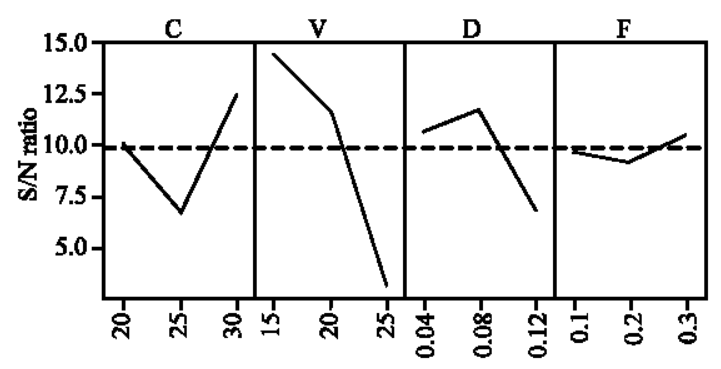

Fig. 3: $\mathrm{S} / \mathrm{N}$ ratio graph for $\mathrm{Ra}$

the highest grey relational grade between the reference sequence and itself that alternative will be the best choice.

If the range and unit in one data sequence of a response parameter differ from the others then data preprocessing in Grey relational analysis is required. If the sequence range is excessively large and the standard value is too high then the effect of some factors needs to be ignored.

The process of transferring the original data sequence to a comparable sequence is called normalization. The original data are normalized into the range between zero and one. If higher value indicates the better performance such as MRR then it is normalized as per equation:

$$
X_{i j}=\frac{Y_{i j-} \operatorname{Min}\left[Y_{i j}, i=1,2, \ldots n\right]}{\operatorname{Max}\left[Y_{i j}, i=1,2 \ldots n\right]-\operatorname{Min}\left[Y_{i j}, i=1,2, \ldots n\right]}
$$

If lower value indicates better performance such as $R_{a}$ then it is expressed as:

$$
X_{i j}=\frac{\operatorname{Max}\left[Y_{i j}, i=1,2, \ldots n\right]-Y_{i j}}{\operatorname{Max}\left[Y_{i j}, i-1,2, \ldots n\right]-\operatorname{Min}\left[Y_{i j}, i=1,2, \ldots n\right]}
$$

The grey relational coefficient is determined to express the relationship between reference and actual normalized experimental data. Reference data is the best data which is expressed as $\mathrm{X}_{0}$. The grey relational coefficient can be calculated as:

$$
\mathrm{Y}\left(\mathrm{X}_{\mathrm{oj}}, \mathrm{X}_{\mathrm{ij}}\right)=\frac{\nabla_{\min }+\zeta \nabla_{\max }}{\nabla_{\mathrm{ij}}+\zeta \nabla_{\max }}[\mathrm{i}=1,2, \ldots \text { and } \mathrm{j}=1,2, \ldots \mathrm{m}]
$$

Where:

$$
\nabla_{\mathrm{ij}}=\left|\mathrm{X}_{\mathrm{oj}}-\mathrm{X}_{\mathrm{ij}}\right| \nabla_{\min }=\operatorname{Min}\left\lfloor\nabla_{\mathrm{ij}}, \mathrm{i}=1,2, \ldots \mathrm{n} \& \mathrm{j}=1,2, \ldots \mathrm{m}\right\rfloor
$$

and:

$$
\nabla_{\max }=\operatorname{Max}\left\lfloor\nabla_{\mathrm{ij}}, \mathrm{i}=1,2, \ldots \mathrm{n} \& \mathrm{j}=1,2, \ldots \mathrm{m}\right\rfloor
$$

$\zeta$ is the distinguishing coefficient that is defined in the range between $0-1$. Generally, the distinguishing coefficient can be adjusted to fit the practical requirements. The grey relational grade can be determined as the average of the grey relational coefficients associated with each response parameter. It can be expressed as follows:

$$
\Gamma\left(\mathrm{X}_{0}, \mathrm{X}_{\mathrm{i}}\right)=\frac{1}{\mathrm{~m}} \sum_{\mathrm{j}=1}^{\mathrm{m}} \mathrm{Y}\left(\mathrm{X}_{\mathrm{oj}}, \mathrm{X}_{\mathrm{ij}}\right)
$$

Where $\mathrm{m}$ is the number of response parameter. In relation to the present study, the two responses i.e., MRR and $\mathrm{Ra}$ have got different level of importance. ECG primarily being a finishing operation, emphasis is given on Ra rather than on MRR leading to an assignment of biased weights to the 2 attributes. In this experimentation, 70 and $30 \%$ weights are assigned to MRR and $\mathrm{Ra}$, respectively. Generally, a high value of the grey relational grade corresponds to a strong relation between the reference data sequence and the comparative sequence. As mentioned before, the reference data is the best response of the experimental results.

Therefore, a higher value of the grey relational grade means that the corresponding machining parameters are closer to the optimal levels. In other words, the optimization of machining parameters associated with the complex multiple response parameters can be converted into the optimal resolution of single grey relational grade. Table 10 shows the results of grey relational coefficients, grey relational grades and their ranks. The results show that experiment number 8 has the largest grey relational grade. So, it is expected that the machining parameter setting of this experiment will fulfill multiple response parameters optimization.

Determination of optimum machining parameters: In this study, optimal machining parameters with considerations of the multiple performance characteristics are obtained and verified. ANOVA for multiple performance characteristics is carried out to investigate the prominent variables that have significant consequences. Table 11 
Table 10: Grey relational coefficients and grades

\begin{tabular}{|c|c|c|c|c|c|c|c|c|}
\hline \multirow[b]{2}{*}{ Expt. no. } & \multicolumn{2}{|c|}{ Normalizing } & \multicolumn{2}{|l|}{ Delta } & \multicolumn{2}{|c|}{ Grey coefficient } & \multirow[b]{2}{*}{ Grey grade } & \multirow[b]{2}{*}{ Rank } \\
\hline & MRR & $\mathrm{Ra}$ & MRR & $\mathrm{Ra}$ & MRR & $\mathrm{Ra}$ & & \\
\hline 1 & 0.024605 & 0.990291 & 0.975395 & 0.009709 & 0.235221 & 0.986320 & 0.7610 & 3 \\
\hline 2 & 0.154657 & 0.949691 & 0.845343 & 0.050309 & 0.261930 & 0.932949 & 0.7316 & 5 \\
\hline 3 & 0.000000 & 0.399823 & 1.000000 & 0.600177 & 0.230769 & 0.538388 & 0.4461 & 8 \\
\hline 4 & 0.126538 & 0.966461 & 0.873462 & 0.033539 & 0.255654 & 0.954277 & 0.7447 & 4 \\
\hline 5 & 0.172232 & 0.683142 & 0.827768 & 0.316858 & 0.266012 & 0.688395 & 0.5617 & 7 \\
\hline 6 & 0.045694 & 0.323036 & 0.954306 & 0.676964 & 0.239176 & 0.508365 & 0.4276 & 9 \\
\hline 7 & 0.562390 & 0.956752 & 0.437610 & 0.043248 & 0.406719 & 0.941812 & 0.7813 & 2 \\
\hline 8 & 0.827768 & 1.000000 & 0.172232 & 0.000000 & 0.635281 & 1.000000 & 0.8906 & 1 \\
\hline 9 & 0.070299 & 0.783760 & 0.929701 & 0.216240 & 0.243962 & 0.763992 & 0.6080 & 6 \\
\hline
\end{tabular}

Table 11: ANOVA for multiple performances

\begin{tabular}{lccccc}
$\begin{array}{l}\text { Process } \\
\text { parameter }\end{array}$ & DOF & $\begin{array}{c}\text { Sum } \\
\text { of squares }\end{array}$ & $\begin{array}{c}\text { Adjusted } \\
\text { mean square }\end{array}$ & F-value & $\begin{array}{c}\text { Contribution } \\
(\%)\end{array}$ \\
\hline C & 2 & 0.050730 & 0.025351 & 4.2650 & 25.03 \\
V & 2 & 0.128020 & 0.064012 & 10.7700 & 63.22 \\
D & 2 & 0.019030 & 0.009518 & 1.6013 & 9.40 \\
F & 2 & 0.004740 & 0.002370 & 0.4000 & 2.35 \\
Error & 0 & 0.000000 & 0.000000 & - & - \\
Total & 8 & 0.202500 & - & 17.0363 & - \\
Error & 4 & 0.023776 & 0.005940 & - & - \\
\hline
\end{tabular}

Table 12: Response table for determination of optimum level setting

\begin{tabular}{lllllc}
\hline Factors & Level 1 & Level 2 & Level 3 & ABS (max-min) & Rank \\
\hline C & 0.6462 & 0.57799 & 0.7600 & 0.18201 & 2 \\
V & 0.7623 & 0.72800 & 0.4939 & 0.26840 & 1 \\
D & 0.6931 & 0.69480 & 0.5964 & 0.09840 & 3 \\
F & 0.6436 & 0.64680 & 0.6938 & 0.05020 & 4 \\
\hline
\end{tabular}

Total mean value of the grey relational grade is 0.6614

clearly shows that voltage $(63.22 \%)$ and concentration $(25.03 \%)$ have pronounced effect on the multiple performances. The grade corresponding to each control factor at their levels are calculated as shown in Table 12 and subsequently, the overall mean is calculated. Then, the absolute value which is the difference between the maximum and minimum value of each factor considering different levels of grey relational grade is computed as shown in Table 12. The optimum level setting for the control factor is selected corresponding to the maximum value of the level of each factor of Table 12.

Total mean value of the grey relational grade is 0.6614 . Figure 4 shows the grey relational grade graph where the dashed line is the value of the total mean of the grey relational grade.

The larger the grey relational grade, the better are the multiple performance characteristics. However, the relative importance among the process parameters for the multiple performance characteristics still needs to be known so that the optimal combinations of the process parameter levels can be determined.

Confirmation test: Once the optimal level of the machining parameters is selected, the final step is to predict and verify the improvement of the performance characteristic using the optimal level of the machining
Table 13: Results of machining performance using the initial and optimal machining parameters

\begin{tabular}{|c|c|c|c|}
\hline \multirow[b]{2}{*}{ Setting levels } & \multirow[b]{2}{*}{$\begin{array}{l}\text { Initial machining } \\
\text { parameters } \\
\text { C1-V1-D1-F1 }\end{array}$} & \multicolumn{2}{|c|}{ Optimal machining parameters } \\
\hline & & $\begin{array}{l}\text { Prediction } \\
\text { C3-V1-D1-F3 }\end{array}$ & $\begin{array}{r}\text { Experiment } \\
\text { C3-V1-D1-F3 }\end{array}$ \\
\hline $\operatorname{MRR}\left(\mathrm{g} \mathrm{min}^{-1}\right)$ & 0.0670 & 0.5240 & 0.5170 \\
\hline $\mathrm{Ra}(\mu \mathrm{m})$ & 0.1680 & 0.1570 & 0.1600 \\
\hline Grey relation grade & 0.7610 & 0.8906 & 0.8831 \\
\hline
\end{tabular}

Improvement of the grey relation grade: 0.1204

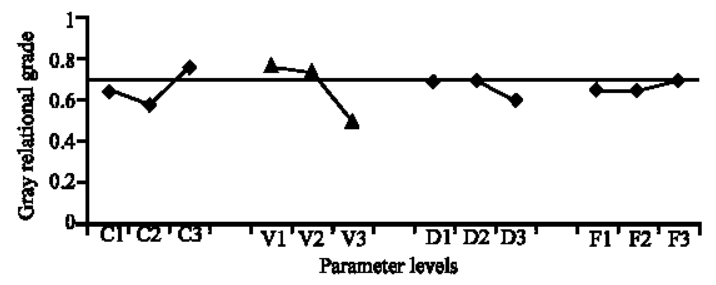

Fig. 4: Grey relational response graph

parameters. The estimated grey relational grade using the optimal level of the machining parameters can be calculated as:

$$
\hat{\psi}=\psi_{\mathrm{m}}+\sum_{\mathrm{i}=1}^{\mathrm{q}}\left(\bar{\psi}_{\mathrm{i}}-\psi_{\mathrm{m}}\right)
$$

Where:

$\Psi_{\mathrm{m}}=$ Total mean of the grey relational grade

$\bar{\psi}_{i}=$ Mean of the grey relational grade at the optimal level

$\mathrm{q}=$ Number of the machining parameters that significantly influence the multiple performance characteristics

Table 13 shows the results of the confirmation experiment employing the optimal machining parameters. It is found that MRR increases by $0.45 \mathrm{~g} \mathrm{~min}^{-1}$ and improvement in the $\mathrm{Ra}$ is by $0.008 \mu \mathrm{M}$.

\section{CONCLUSION}

The present study attempts to optimize the machining variables by combining grey relational analysis and the Taguchi method while machining of alumina-aluminium 
IPC by ECG. The $\mathrm{S} / \mathrm{N}$ ratio shows that high concentration and low voltage augurs well for both high MRR and lower Ra. Based on the results of analysis, it is concluded that voltage and electrolyte concentration plays significant role in governing high MRR and low Ra.

Increase in the machining voltage encourages decomposition potential to attain an optimum level beyond which over potential adversely affects the MRR. As the machining voltage increases, the current density increases and more and more aluminum gets dissolved into the solution exposing $\mathrm{Al}_{2} \mathrm{O}_{3}$ texture that results in rough surface.

MRR follows an increasing trend with electrolyte concentration owing to the fact that it facilitates more aluminum to be ionized into the solution. At the lowest level of concentration, electrochemical dissolution is low hence, mechanical abrasion is predominant. With the increase in the concentration the dissolution rate increases. This causes the $\mathrm{Al}_{2} \mathrm{O}_{3}$ texture to expose which makes the surface rough. The other 2 variables namely depth of cut and electrolyte flow rate are insignificant to affect the responses.

The Grey relational analysis converts optimization of the multiple characteristics into optimization of a single function called grey relational grade which simplifies the computation.

The grey analysis establishes the ranks of output for different variables combinations. It is found that both MRR and Ra improve considerably (as evident from computational results) by using optimal machining variables combinations. It is concluded that the Grey relational analysis is a powerful method to study the effects of different process variables on multiple performance for complex process like ECG.

\section{REFERENCES}

Atkinson, J. and C.F. Nobel, 1987. The Surface Finish Resulting from Peripheral Electrochemical Grinding. 22nd Edn., MTDR, University of Manchester, UK., pp: 371-387.

Benedict, G.F., 1987. Non Traditional Manufacturing Process. Marcel Dekker Inc., New York.

Bhowmick, T.P. and P.K. Mishra, 2000. An investigation on material removal rate by electrochemical grinding process. Proceedings of the International Conference on Manufacturing, Feb. 24-26, Dhaka, pp: 250-256.

Deng, J., 1989. Introduction to grey system. J. Grey Syst., 1: $1-24$.

El-Hofy, H., 2005. Advanced Machining Processes: Nontraditional and Hybrid Machining Processes. McGraw-Hill, New York.
Kao, P.S. and H. Hocheng, 2003. Optimization of electrochemical polishing of stainless steel by grey relational analysis. J. Mater. Process. Technol., 140: 255-259.

Kuo, Y., T. Yang and G.W. Huang, 2008. The use of grey relational analysis in solving multiple attribute decision-making problems. Comput. Ind. Eng., 55: 80-93.

Lin, C.L., 2004. Use of the taguchi method and grey relational analysis to optimize turning operations with multiple performance characteristics. Mater. Manuf. Process., 19: 209-220.

Lin, J.L. and C.L. Lin, 2002. The use of the orthogonal array with grey relational analysis to optimize the electrical discharge machining process with multiple performance characteristics. Int. J. Machine Tools Manuf., 42: 237-244.

Lin, Y. and S. Liu, 2004. A historical introduction to grey systems theory. Proceedings of the IEEE International Conference on Systems, Man and Cybernetics, (ICSMC'04), Hague, Netherlands, pp: 2403-2408.

Lu, H.S., J.Y. Chen and C.T. Chung, 2008. The optimal cutting parameter design of rough cutting process in side milling. J. Achievements Mater. Manuf. Eng., 29: 183-186.

Lu, M. and K. Wevers, 2007. Grey system theory and applications: A way forward. J. Grey Syst., 10: 47-54.

Montgomery, D.C., 2003. Design and Analysis of Experiments. John Wiley and Sons, Inc., New York .

Park, S.A., 1996. Robust Design and Analysis for Quality Engineering. 1st Edn., Chapman and Hall, London, ISBN: 0412556200.

Phadke, M.S., 1989. Quality Engineering Using Robust Design. Prentice Hall, Englewood Cliff, New Jersey.

Reddy, K.H.P., B. Ramamoorthy and P.K. Nair, 2000. Estimation of optimum grinding conditions for better surface finish by applying taguchi techniques. Proceedings of the Internal Conference on Manufacturing, Feb. 24-26, Dhaka, pp: 402-410.

Taguchi, G., 1986. Introduction to Quality Engineering. Asian Productivity Organization, New York.

Tsao, C.C., 2009. Grey-taguchi method to optimize milling parameters of aluminum alloy. Int. J. Adv. Manuf. Technol., 40: 41-48.

Wang, Z., L. Zhu and J.H. Wu, 1996. Grey relational analysis of correlation of errors in measurement. J. Grey Syst., 8: 73-78.

Yan-Min, X., Y. Hu-Ping, C. Jun and R. Xue-Yu, 2007. Application of grey relational analysis in sheet metal forming for multi-response quality characteristics. J. Zhejiang Univ. Sci. A, 8: 805-811. 